\title{
POLÍCIA POLÍTICA, INTELIGÊNCIA E SEGURANÇA NA DITADURA MILITAR (1964-1984)
}

\author{
Thiago da Silva Pacheco
}

As atuais organizações de Inteligência de Segurança - Security Intelligence - surgiram na primeira metade do século XIX, decorrentes do temor causado pelos movimentos operários, anarquistas ou inspirados pela Revolução Francesa. As polícias europeias desenvolveram técnicas de "vigilância, infiltração, recrutamento de informantes e interceptação de mensagens", absorvendo também aspectos científicos - conforme padrões daquele século - voltados para a investigação criminal. ${ }^{2}$ Aquelas polícias eram políticas, posto que seu objetivo era lidar com o crime político, isto é, a oposição ao Estado. E eram secretas, por lançarem mão de métodos de espionagem.

A partir de então, as atividades de Polícia Secreta tornaram-se mais institucionalizadas e internacionalizadas. Foi o caso, por exemplo, da Sûreté e da Okhrana que, respectivamente em 1870 e 1882, já mantinham redes de agentes no exterior. De forma semelhante, após o fim da Primeira Guerra Mundial, o FBI passou a operar contra espionagem, atuando secretamente na América Latina e outros continentes por meio de contatos com as polícias locais. ${ }^{4}$

Foi também após a Primeira Guerra Mundial que estas polícias especializaram-se na atividade de contra espionagem, ao estabelecer vigilância regular sobre os serviços de Inteligência estrangeiros que operassem dentro do território nacional. De fato, argumenta Herman ${ }^{5}$ que a Primeira Grande Guerra intensificara a nível continental a necessidade de contra espionagem e contra sabotagem. Este quadro veio se acentuando após a Revolução Russa e a ameaça do comunismo, principalmente depois da Segunda Guerra Mundial, como contramedidas à espionagem e outras operações da União Soviética ou de partidos comunistas nacionais que se opusessem ao governo.

No Brasil, vemos estas atribuições de Inteligência atreladas a departamentos específicos da polícia investigativa desde o início do século XX. Tratava-se de departamentos organizados enquanto delegacias ou divisões "de ordem política e social", os quais realizavam coleta e análise de dados pertinentes aos mais variados grupos e indivíduos - nacionais e estrangeiros - considerados perigosos conforme o projeto político do Estado. ${ }^{6}$ Isto se manteve pelo menos até o Golpe Civil-Militar de 1964, quando, como teremos a oportunidade de demonstrar, a importância dos departamentos de Polícia Política neste tipo de situação foi redimensionada dentro do Sistema de Informações construído pelos governos militares. ${ }^{7}$

Entretanto, os estudos que abordam a Polícia Política enquanto instituição não tem tratado especificamente das funções policiais com relação à atividade de Inteligência. Elizabeth Cancelli, autora de importante trabalho sobre a polícia durante a Era Vargas ${ }^{8}$, analisa o uso de verbas secretas,

\footnotetext{
${ }^{1}$ Formado em História pela Universidade Gama Filho (2006), Mestre e Doutor em História pelo Programa de Pós-Graduação em História Comparada da UFRJ (PPGHC - UFRJ), atualmente em estágio pós-doutoral no Programa de Pós-Graduação em Direito da Faculdade Nacional de Direito (PPGD-FND/UFRJ).E-mail: <pacheco.tsp@gmail.com>.

${ }^{2}$ CEPIK, Marco A. C. Espionagem e democracia. Rio de Janeiro: FGV. 2003, p. 99.

${ }^{3}$ Sûreté e a Okhrana eram os órgãos de policiamento político e secreto respectivamente da França e da Rússia no século XIX. Sobre a internacionalização das Polícias Políticas, cf. HERMAN, Michael. Intelligence power in peace and war. Cambridge: Cambridge University Press, 1996, p. 19, 20.

${ }^{4}$ HUGGINS, Martha K. Polícia e Política: relações Estados Unidos/América Latina. São Paulo: Cortez, 1998; e WHEELER, Douglas L. A Guide to the History of Intelligence 1800-1918. AFIO's Intelligencer Journal, Volume 19, Number 1, 2012.

${ }^{5}$ HERMAN, Intelligence power in peace and war..., p. 20-21.

${ }^{6} \mathrm{O}$ policiamento de natureza política iniciou-se no Distrito Federal nos primórdios do século XX, e os demais estados criaram suas Delegacias de Ordem Política e Social durante os anos 1920 e 1930. Ver REZNIK, Luís. Democracia e Segurança Nacional: A Polícia Política no pós-guerra. Rio de Janeiro: Editora FGV, 2004, p.105-108; e ARQUIVO PÚBLICO DO ESTADO DO RIO DE JANEIRO. Os Arquivos das Polícias Políticas: reflexos de nossa história contemporânea. Rio de Janeiro: APERJ, 1993.

${ }^{7}$ FICO, Carlos. Como eles agiam: Os subterrâneos da ditadura militar: Espionagem e Polícia Política. São Paulo: Record, 2001.
}

${ }^{8}$ CANCELLI, Elizabeth. O mundo da violência: a polícia na Era Vargas. 2.ed. Brasília: Ed. UnB, 1994. 
espionagem e colaboração com outras agências por parte da polícia brasileira. Marcos Tarcísio Florindo, por sua vez, tratou do assunto da espionagem ao investigar o Serviço Reservado do DOPS de São Paulo no mesmo período. ${ }^{9}$ Em ambos os trabalhos foi abordado como a Polícia Política utilizava-se de espiões ou delatores, e atuava como um serviço secreto. Estas duas atividades, sem dúvida, estão relacionadas ao trabalho de Inteligência, na medida em que este consiste na "coleta de informações sem o consentimento, cooperação ou mesmo conhecimento por parte dos alvos em questão". ${ }^{10} \mathrm{Ou}$ seja, o segredo é uma necessidade recorrente para a atividade de Inteligência ${ }^{11} e$ a espionagem, um dos muitos métodos empregados. ${ }^{12}$ Mas a atividade em si consiste na coleta de dados $e$ na produção de informações que, no caso especifico da Inteligência doméstica, voltada para a Segurança interna, vem a ser "informações sobre identidades, capacidades, intenções e ações de grupos e indivíduos dentro de um país, cujas atividades são ilegais ou alegadamente ilegítimas". ${ }^{13}$

Levando a função de coleta de dados e produção de informações em consideração, Luís Reznik ${ }^{14}$ analisou a documentação produzida pela Polícia Política durante o contexto democrático entre 1946 e 1964. A partir da construção de uma ideia de Segurança Nacional - cristalizada em lei no ano de 1953 - Reznik explica como se organizava o aparato policial que produzia informações referentes àquela ideia, inclusive por meio de uma rede internacional de cooperação no esforço contra o comunismo no contexto da Guerra Fria.

Especificamente com relação ao regime estabelecido a partir do golpe de 1964, Carlos Fico ${ }^{15}$ investigou como se estruturavam os Sistemas de Informações e de Segurança instaurados naquele contexto. Mapeando o Sistema de Informações encabeçado pelo Serviço Nacional de Informações, no qual se inseriam os serviços de Inteligência das Forças Armadas e o trabalho investigativo das Polícias Políticas de cada estado - então chamadas de DOPS ou DEOPS ${ }^{16}$ - Fico oferece uma descrição minuciosa dos procedimentos e perspectivas dos componentes deste sistema. Neste caso, a função dos DOPS era meramente complementar - daí salientarmos que suas funções foram redimensionadas fosse fornecendo informações ao sistema, fosse atuando em operações de segurança e repressão.

Neste sentido, pretendemos aprofundar o papel do DOPS nos sistemas de Inteligência e Segurança estabelecidos naquele contexto, a partir do conceito de Ciclo de Inteligência, que vem a ser uma ilustração teórica acerca das formas pelas quais agências destinadas a informações e trabalho secreto coletam e processam dados com o fim de produção de conhecimento. ${ }^{17}$ Como esta coleta e análise de dados era posta em prática por organismos policiais, também envolvia a esfera legal e jurídica, voltada para o processo legal de criminosos políticos. Portanto, levamos também em consideração como a produção de informações por parte Polícia Política, na forma de relatórios, dossiês e fichas pessoais ${ }^{18}$, gerava um processo de criminalização ${ }^{19}$ da oposição política aos governos militares em prol do projeto vigente de Segurança Nacional.

O que buscamos demonstrar com esta análise é que o trabalho da Polícia Política atendia a duas demandas: uma secreta, relacionada à produção de informações dentro de um processo de Inteligência doméstica, e outra jurídica, voltada para o processo legal de criminalização dos indivíduos

\footnotetext{
${ }^{9}$ FLORINDO, Marcos Tarcísio. O serviço reservado da Delegacia de Ordem Política e Social de São Paulo na era Vargas. Dissertação (Mestrado em História) - Universidade Estadual Paulista Júlio de Mesquita Filho, UNESP, Franca, 2000.

${ }^{10}$ CEPIK, Marco A. C. Espionagem e democracia..., p. 28.

${ }^{11}$ SHULSKY, Abram. What is Intelligence? Secrets and competition among states. In: GODSON, Roy; SCHMITT, G.; MAY, E. US Intelligence at the crossroads: agendas for reform. New York: Brassey's, 1995.

${ }^{12}$ A espionagem faz parte do que normalmente se chama de Humint. Este termo seria "um eufemismo tipicamente norteamericano, incorporado ao jargão internacional porque evita o uso do termo espionagem, muito mais pesado do ponto de vista legal e político". Trata-se, neste caso, dos dados adquiridos e transmitidos por pessoas. Falamos aqui de espiões ou informantes recrutados, treinados, pagos e/ou infiltrados por uma agência, mas este tipo de dado também ser provido por patrulhas de policiais ou soldados, colaboradores esporádicos sem vínculo formal com a agência, denúncias, etc. CEPIK, Marco A. C. Espionagem e democracia..., p. 26.

${ }^{13}$ CEPIK. Marco A. C. Glossário de termos, siglas e acrônimos, 1999.

${ }^{14}$ REZNIK, Luís. Democracia e Segurança Nacional...

${ }^{15}$ FICO, Carlos. Como eles agiam...

${ }^{16}$ Departamento ou Divisão de Ordem Política e Social.

${ }^{17}$ Sobre o Ciclo de Inteligência, ver CEPIK, Marco A. C. Espionagem e democracia...; e ANTUNES, Priscila C. B. SNI \& Abin: uma leitura dos serviços secretos brasileiros ao longo do século XX. Rio de Janeiro: FGV, 2002.

${ }^{18}$ ARQUIVO PÚBLICO DO ESTADO DO RIO DE JANEIRO. Os Arquivos das Polícias Políticas...

${ }^{19}$ Conforme a perspectiva da criminologia crítica. Ver BARATTA, Alessandro. Criminologia Crítica e Crítica do Direito Penal. Rio de Janeiro: Revan, 2002.
} 
e grupos que seu opunham ao regime. Como os limites entre as duas atividades não eram claros, o caráter secreto e o projeto de Segurança pretendido pelos governos de então propiciavam práticas extralegais como assassinatos, sequestros e tortura por parte da Polícia Política e de outros órgãos de repressão.

\section{A Polícia Política na ditadura de 1964}

As Divisões de Polícia Política de cada estado - Rio de Janeiro e São Paulo em especial ${ }^{20}$ - foram fundamentais para a atividade de Inteligência de Segurança até a segunda metade dos anos 1950. Esta mudança começou a partir de 1946, quando a atribuição de Inteligência passou especificamente para o Serviço Federal de Informações e Contra-Informações (SIFCI). Esta agência foi criada pelo decreto-lei 9.775-A de 6 setembro de 1946, na perspectiva de modernizar a atividade de Inteligência e atualizar tal serviço no Brasil frente às novas necessidades decorrentes do fim da Segunda Guerra Mundial e início da Guerra Fria.

A criação do SIFCI previa um órgão chefiado por militares, concentrando toda a atividade de coleta, processamento e disseminação de informações pertinentes à Defesa e aos interesses do Estado brasileiro. Entretanto, o SIFCI existiu apenas no papel até 1956, quando um grupo composto por três militares e um policial fora enviado para um período de estágio em órgãos americanos - CIA e FBI. Paralelamente, a Polícia Política perdia importância quanto a este quesito: no início da década de 1960, em decorrência da mudança da capital para Brasília, a Polícia Política do Rio de Janeiro foi reestruturada, tornando-se o Departamento de Ordem Polícia e Social - DOPS. Passou, a partir de então, a ser subordinada à Secretaria de Segurança Pública do Estado da Guanabara, assim como os demais departamentos de Polícia Política dos outros estados da federação.

Não obstante, mesmo com esta mudança estrutural, a polícia do Rio de Janeiro centrifugava grande parte das informações produzidas pelos departamentos de Policia Política de outros estados, devido ao papel centralizador por ela exercido em décadas anteriores, quando se constituía na Divisão Política e Social da polícia do Distrito Federal ${ }^{21}$.

A partir de 1964, o DOPS do Rio de Janeiro e dos demais estados foram adaptados ao Sistema de Informações pretendido pelos militares. Tal sistema consistia em um intrincado relacionamento entre instituições federais e estaduais, como os militares consideravam que a limitada jurisdição estadual das policias e seu despreparo tornavam-nas insuficientes para o enfrentamento da ação subversiva. ${ }^{22}$ Assim, em torno do Serviço Nacional de Informações - SNI, criado em 1964 a fim de substituir o SFICI - atuavam as seções de Inteligência do Exército, da Marinha, da Aeronáutica e das Polícias Militares, os próprios Departamentos de Ordem Política e Social de cada estado e Divisões de Segurança e Informações especialmente criadas dentro dos ministérios civis. ${ }^{23}$

Este sistema, chamado de Sistema Nacional de Informações - Sisni - não foi, evidentemente, criado do nada. Sua "planta baixa" já estava lançada desde o Estado Novo, com a criação das Seções de Segurança Nacional de cada ministério civil, complementado pelo projeto do SFICI em 1946 e, claro, pela atuação dos departamentos de Polícia Política do Distrito Federal e demais estados da federação. ${ }^{24}$ Não obstante, apesar da substituição do SFICI pelo SNI ter se dado logo nos primeiros meses do novo regime, o SISNI foi se estruturando até consolidar-se em 1968, após chegada de Costa e Silva e a ala mais radical dos militares ao poder. ${ }^{25}$

De qualquer forma, a função dos DOPS neste sistema era, como já mencionamos, complementar, e isto mesmo antes da estruturação do Sisni. Apesar dos militares considerarem que os policiais fossem

\footnotetext{
${ }^{20} \mathrm{O}$ DOPS do Rio e de São Paulo eram os únicos com alguma capacidade de combate à subversão reconhecida pelos militares, sendo a polícia paulista tida como muito melhor organizada e preparada. D'ARAUJO, Maria Celina; SOARES, Glaucio Ari Dilson; CASTRO, Celso (org.). Os anos de Chumbo: a memória militar sobre a repressão. Rio de Janeiro: Relume-Dumará, 1994.

${ }^{21}$ ARQUIVO PÚBLICO DO ESTADO DO RIO DE JANEIRO. Os Arquivos das Polícias Políticas: reflexos de nossa história contemporânea.

${ }^{22}$ D'ARAUJO, Maria Celina; SOARES, Glaucio A. D.; CASTRO, Celso (org.). Os anos de Chumbo...

${ }^{23}$ FICO, Carlos. Como eles agiam...

${ }^{24}$ ARAUJO, Paulo Roberto de; DUARTE, Leila Menezes de. Ação e investigação: polícia política e comunismo no Brasil 1945-1964. Rio de Janeiro: APERJ, 2000; e REZNIK, Luís. Democracia e Segurança Nacional...

${ }^{25}$ FICO, Carlos. Como eles agiam...
} 
corruptos e descompromissados com o patriotismo ${ }^{26}$, desde o início da ditadura tiveram dificuldades em levar a cabo uma ampla repressão sem os departamentos de policiamento político. Isto porque aqueles órgãos - em especial o de São Paulo, melhor organizado do Brasil, e o do Rio, com ampla documentação por ter sido a polícia da capital da República - eram especializados em investigação $e$ burocracia judicial, além de detentores de extenso arquivo com prontuários, fichas, relatórios $e$ investigações sobre atuação comunista. Tratava-se de um volume de informações por demais importante para ser ignorado pelos militares.

Assim, os DOPS conferiam ao Sistema Nacional de Informações aparato técnico, judicial $e$ burocrático inerente ao trabalho de polícia investigativa e judiciária, que era estranho às Forças Armadas. Também forneciam dados sobre instituições e indivíduos, cujo passado, sobretudo na forma de atuação política de um cidadão, estavam arquivados em forma de prontuários.

Neste sentido, para compreendermos a função policial neste sistema, recorremos ao conceito de Ciclo Inteligência, que vem a ser o processo por meio do qual os dados são coletados $e$ analisados, produzindo-se o conhecimento que será colocado à disposição dos usuários. Este processo atravessa dez fases bem definidas: requerimentos informacionais; planejamento; gerenciamento dos meios técnicos de coleta; coleta a partir das fontes - informantes, espiões, captação e sinais, etc -; processamento; análise das informações obtidas das fontes; produção de relatórios, informes e estudos; disseminação dos produtos; consumo pelos usuários e avaliação. Resumidamente, este ciclo compreende a coleta de dados por fontes ostensivas ou agências especializadas, a análise $e$ disseminação deste material, o alto nível de avaliação e, por fim, a entrega do produto final ao destinatário $^{27}$, que normalmente é um chefe de estado ou comandante. Tal produto de Inteligência objetiva subsidiar ao destinatário no processo de tomada de decisões.

Note-se que esta estrutura do ciclo de Inteligência é somente uma ilustração ${ }^{28}$, sendo cada caso específico sobre como estes processos ocorrem - quando de fato ocorrem. Neste sentido, usamos esta ilustração para compreender o papel do DOPS no Sistema de Informações estabelecido pelos militares.

Os DOPS operavam coleta de dados por meio de seus serviços reservados, infiltrando agentes, realizando observações reservadas, violando correspondências e grampeando telefones. ${ }^{29}$ Não obstante, a coleta de dados não era a função principal da Polícia Política: esta cabia ao SNI. A principal função dos DOPS estava na fase seguinte do Ciclo de Inteligência, que vem a ser a análise e processamento dos dados coletados, isto é, a averiguação, cotejamento e acareação das informações obtidas.

É aqui que entram os arquivos policiais. Na documentação referente ao período, o DOPS recebia e fornecia dados recolhidos por outros órgãos do sistema, notadamente o SNI e as seções de Inteligência do Exército, da Marinha e da Aeronáutica, num fluxo constante de informações. Noutra direção, são constantes Pedidos de Busca por parte das Forças Armadas e do SNI junto aos arquivos policiais: esses Pedidos de Busca vinham organizados por origem, difusão e o pedido propriamente dito, sendo origem o órgão originário tanto da investigação em andamento quanto do próprio pedido, sempre apresentado em siglas como SNI (Serviço Nacional de Informações), E-2 (Exército), MR (Marinha) e A2 (Força Aérea). ${ }^{30}$

Assim, os DOPS repassavam informações - outrora produzidas pela polícia e que eram abundantes em seus arquivos - a outros órgãos do sistema, ou produziam novas informações por meio de investigações, interrogatórios e acareações. Já as estratégias de Inteligência e produção de conhecimento cabiam ao Serviço Nacional de Informações e às seções de Inteligências das Forças Armadas. O estágio do Alto Nível de Avaliação - ou seja, a reunião entre vários departamentos a fim de se construir uma opinião sobre determinada questão - era posto em prática pelo Conselho de

\footnotetext{
${ }^{26}$ D'ARAUJO, Maria Celina; SOARES, Glaucio A. D.; CASTRO, Celso (org.). Os anos de Chumbo...

${ }^{27}$ CEPIK, Marco A. C. Espionagem e democracia... p. 32; e ANTUNES, Priscila C. B. SNI \& Abin..., p. 28-29.

${ }^{28}$ CEPIK, Marco A. C. Espionagem e democracia... p. 32; e ANTUNES, Priscila C. B. SNI \& Abin..., p. 28-29.

${ }^{29}$ Sobre a menção aos serviços reservados, ver "Relatório mensal na área do Rio de Janeiro". Arquivo Público do Estado do Rio de Janeiro. Fundo Polícias Políticas. Setor DGIE. Pasta 302. Sobre a infiltração, o Relatório Geral de fevereiro de 1967. O Fundo Polícias Políticas, Pasta 30, menciona um agente especialmente destacado para assistir a uma reunião no Tribunal Regional do Trabalho do Rio de Janeiro. Acerca das observações reservadas, violações de correspondências e grampeamento de telefones, ver Relatório Reservado. Setor DOPS. Pasta 111.

${ }^{30}$ ARQUIVO PÚBLICO DO ESTADO DO RIO DE JANEIRO. Fundo Polícias Políticas. Relatórios Anuais produzidos entre 1964-1983. 
Segurança Nacional. E o principal consumidor da Inteligência produzida era o presidente da República ou, eventualmente, órgãos de segurança que lidavam com a repressão direta.

Portanto, a organização dos arquivos policiais, com função importante dentro do Sistema Nacional de Informações, nos permite compreender como o quadro de ameaças a Segurança Interna foi construído segundo uma lógica policial de desconfiança, repressão e ordenamento do pensamento político.

\section{Os Arquivos Policiais}

Em 1975, o DGIE - Departamento Geral de Investigações Especiais, nome dado ao DOPS do Rio de Janeiro a partir daquele ano - organizou a documentação do órgão em 58 Setores Temáticos, referentes a meios sociais, instituições ou procedimentos policiais. Nota-se que alguns destes setores, como "Estudantil", "Terrorismo" e "Informações Solicitadas", foram criados no decorrer do regime de 1964, expondo o processo de adaptação do órgão à nova realidade. Há também aqueles Setores Temáticos que correspondem à fusão dos Estados do Rio e da Guanabara, como o Setor Municípios ${ }^{31}$ por exemplo. Já os setores referentes aos Ministérios - da Justiça, da Saúde, da Aeronáutica, da Marinha, do Trabalho, do Interior e das Minas e Energia - contêm Pedidos de Busca junto aos arquivos policiais acerca dos antecedentes de indivíduos que porventura trabalhassem naqueles ministérios. ${ }^{32}$ Produzidos entre 1965 e 1974, esta documentação demonstra a preocupação com a ideologia política dos indivíduos dentro do próprio Estado, criminalizando o funcionário público não estivesse alinhado ao projeto do regime.

Mas este processo não se restringiu aos órgãos do próprio Estado: desde o período democrático iniciado em 1946 a Polícia Política temia os movimentos sociais, as organizações de classe, os grupos estudantis e os sindicatos. Negando-lhes protagonismo e liberdade de participação política, tratava-os como massas suscetíveis a condução, que poderiam ser manobradas pelos comunistas em seus planos de derrubada da democracia. Na verdade, alguns destes movimentos vinham sendo classificados pela polícia como meras fachadas para a atuação do $\mathrm{PCB} .{ }^{33}$ Assim, tanto as organizações sociais e de classe eram meios de desordem e de "baderna" quanto espaços vulneráveis ao controle subversivo.

Por exemplo, os trabalhos policiais referentes ao Setor Estudantil começaram em 1965 e encerraram-se somente em 1982, o que demonstra a vigilância contínua sobre este meio em praticamente todo o período ditatorial. A documentação consiste de levantamentos de dados, relatórios e fichas sobre estudantes e professores com relação às suas atividades culturais e políticas. Em especial, preocupava a polícia e aos demais órgãos do sistema que estudantes e professores adotassem perspectivas esquerdistas $e$ as manifestasse nas escolas, agremiações $e$ faculdades. Tal preocupação se expressa em relatórios como a averiguação dos antecedentes políticos de estudantes da Faculdade Nacional de Direito que, em 1965, tentavam rearticular o movimento estudantil naquela faculdade por meio do "CACO Livre"; na investigação sobre o Movimento Trotskista Estudantil, que estaria tentando recrutar estudantes de nível médio e universitário; ou no relatório de 1966 sobre a greve geral planejada por estudantes, alegadamente envolvidos com o PCB, que estariam "tumultuando o meio universitário por sucessivas manifestações de protestos (...) contra a política educacional do governo". Da mesma forma, chapas que concorriam em grêmios estudantis eram investigadas por serem compostas por esquerdistas e controladas pelo Partido Comunista, como a que concorreu para o diretório acadêmico na Faculdade Nacional de Filosofia também em $1966 .{ }^{34}$

Particularmente reveladores são os termos "agitação" e "proselitismo" usados nos relatórios, como vemos no informe da Marinha, o qual denunciava estar a "Escola Técnica Federal da Guanabara “(...)

\footnotetext{
${ }^{31}$ ARQUIVO PÚBLICO DO ESTADO DO RIO DE JANEIRO. Os Arquivos das Polícias Políticas..., p. 29.

${ }^{32}$ ARQUIVO PÚBLICO DO ESTADO DO RIO DE JANEIRO. Os Arquivos das Polícias Políticas..., p. 33-34.

${ }^{33}$ ARQUIVO PÚBLICO DO ESTADO DO RIO DE JANEIRO. Relatório das atividades do Serviço de Investigações durante o ano de 1948. Fundo Polícia Política, Setor Administração 1E. Cecil de Borer, agente de Polícia Política de alto escalão, alertava, em relatório referente às atividades do Setor Trabalhista datado de 1949, que quanto maior a quantidade de trabalhadores reunidos, mais propensos eles estariam ao "vírus comunista": “(...) as massas trabalhistas representam a base onde o vírus do comunismo é lançado, constituindo-se o campo mais propício para sua disseminação e propagação. Quanto maiores forem as massas trabalhistas congregadas, tanto mais facilmente se constituirá alvo das infiltrações comunistas". Fundo DPS, Notação 00.0028.
}

${ }^{34}$ ARQUIVO PÚBLICO DO ESTADO DO RIO DE JANEIRO. Fundo Polícias Políticas, Setor Estudantil, pasta 1-3. 
sendo palco de constantes agitações estudantis, provocadas por elementos agitadores, possivelmente pertencentes ao PCB". Outro exemplo encontramos nas investigações policiais sobre "subversão" $e$ "proselitismo" na Faculdade Nacional de Filosofia. ${ }^{35}$ Esses "aliciamentos" se davam por indivíduos que a Polícia Política classificava como "perigosíssimo elemento", como foi o caso do informe produzido em 1966 acerca de um sargento do Exército e aluno do curso de História da Faculdade Nacional de Filosofia. ${ }^{36} \mathrm{De}$ fato, ter feito parte do Partido Comunista e/ou ter efetuado panfletagem política consolidava a construção policial em torno da ideia de um infiltrado e agitador, que incitava determinado meio social, sindicato ou grêmio. Isto se deu com os estudantes Raimundo Pinheiro, Roberto Martins e Maria Beatriz, investigados em 1966 por suas ligações com o Partido Comunista. ${ }^{37}$

Preocupação semelhante se dava com relação ao Setor Sindical, cuja documentação começou a ser produzida em 1938 e encerrou-se em 1976. Na documentação produzida a partir de abril de 1964, os antecedentes políticos dos membros das diretorias dos sindicatos eram destacados pela polícia, como se pode notar na vigilância sobre as chapas da Cooperativa de Consumo dos Ferroviários da Estrada de Ferro Central do Brasil, em março de 1970. No relatório, constavam os nomes dos concorrentes e seus antecedentes políticos o que, às vezes, consistia simplesmente em terem assinado manifestos ou feito parte de sociedades civis organizadas antes de $1964 .{ }^{38}$

As reuniões dos sindicatos também eram monitoradas de perto pela Polícia Política, como a vigilância sobre a reunião de Sindicato dos Trabalhadores. ${ }^{39}$ Algumas organizações chegaram, inclusive, a colaborar diretamente com esta vigilância, como o Sindicato dos Trabalhadores do Comércio Armazenador que, em 1965, enviou uma circular a fim de que a polícia apreciasse a composição de suas chapas. ${ }^{40}$ De fato, isto ocorreu desde o início do regime: em 1964, a Associação dos Servidores Civis do Brasil emitiu uma portaria elogiando o Ato Institucional ( $\left.\mathrm{N}^{\circ} 1\right)$ e o "reestabelecimento da democracia integral em nosso país, em benefício de seu povo, pacífico, ordeiro, católico e fundamentalmente patriota". A associação chegou a criar uma comissão especial interna para apurar casos de infiltração comunista. ${ }^{41}$

Foi assim que o Setor Estudantil e o Setor Sindical foram tratados como espaços vulneráveis à atuação de "agitadores" ou divulgadores de ideologia comunista, o que levaria o sindicato ou movimento estudantil a se opor contra o regime. Para a Polícia Política, trabalhadores e estudantes eram considerados suscetíveis a serem influenciados pela atuação de homens e mulheres nesses meios, atuação que era classificada como uma forma de aliciamento, de proliferação de ideias subversivas $e$ nocivas à nação. Destarte, os comunistas atuantes nesses meios eram classificados como gente "infiltrada" - ou seja, vinda de fora - e "agitadores" - ou seja, movimentavam, balançavam, mexiam o que deveria estar em repouso.

Além da militância nestes meios, outra preocupação por parte da Polícia Política foi a ação armada dos grupos de esquerda, que foi classificada como terrorismo tanto pelas leis estabelecidas pelos governos militares quanto pelos órgãos repressores. Aqui estamos diante de uma disputa de sentidos com relação ao termo, na medida em que o crime de terrorismo carece de definição consensual no campo do direito e serve mais a interesses políticos do que à definição de um ato e suas consequências. ${ }^{42}$ Entre as fileiras de alguns setores da esquerda, o próprio Carlos Marighela definia as ações armadas contra a Ditadura como terrorismo, procurando conferir-lhe o sentido de oposição à tirania tal qual era utilizado no século XIX. ${ }^{43}$ Para Marighela, naquele contexto ser “(...) 'violento' ou um 'terrorista' é uma qualidade que enobrece qualquer pessoa honrada, porque é um ato digno de um revolucionário engajado na luta armada contra a vergonhosa ditadura militar e suas atrocidades". ${ }^{44}$

\footnotetext{
${ }^{35}$ ARQUIVO PÚBLICO DO ESTADO DO RIO DE JANEIRO. Fundo Polícias Políticas, Setor Estudantil, pasta 1.

${ }^{36}$ ARQUIVO PÚBLICO DO ESTADO DO RIO DE JANEIRO. Fundo Polícias Políticas, Setor Sindicatos, pasta 17.

${ }^{37}$ ARQUIVO PÚBLICO DO ESTADO DO RIO DE JANEIRO. Fundo Polícias Políticas, Setor Estudantil, pasta 1.

${ }^{38}$ ARQUIVO PÚBLICO DO ESTADO DO RIO DE JANEIRO. Fundo Polícias Políticas, Setor Sindicatos pasta 17.

${ }^{39} \mathrm{O}$ documento, produzido por Mário Borges - chefe da Secção de Buscas Ostensivas do DOPS - não está datado. Mas parece tratar-se de um período anterior a 1974, já que o órgão é chamado de DOPS e não DGIE (Arquivo Público do Estado do Rio de Janeiro. Fundo Polícias Políticas, Setor Estudantil, pasta 1).

${ }^{40}$ ARQUIVO PÚBLICO DO ESTADO DO RIO DE JANEIRO. Fundo Polícias Políticas, Setor Sindicatos, pasta 13.

${ }^{41}$ ARQUIVO PÚBLICO DO ESTADO DO RIO DE JANEIRO. Fundo Polícias Políticas, Setor Sindicatos, pasta 14.

${ }^{42}$ FRAGOSO, Heleno. Terrorismo e Criminalidade Política. Rio de Janeiro: Forense, 1981; e PAMPLONA, Gustavo. Crimes

Políticos, Terrorismo e Extradição: nos passos de Hannah Arendt. Porto Alegre: Simplíssimo, 2011.

${ }^{43}$ FRAGOSO, Heleno. Terrorismo e Criminalidade Política...

${ }^{44}$ MARIGHELA, Carlos. Mini-Manual do Guerrilheiro Urbano. Material Mimeografado, 1969. 
Entre os legisladores dos governos militares, contudo, o terrorismo não foi delimitado de forma clara nas Leis de Segurança Nacional estabelecidas durante o período: o termo foi inserido pela primeira vez na Lei de Segurança Nacional de 1967 (art.25), surgindo novamente na Lei de 1969 (art. 28) e na de 1978 (art. 26). Em nenhum destes artigos o terrorismo sequer foi definido, mas colocado numa lista que incluía "massacre, devastação, saque, roubo, sequestro, incêndio ou depredação, atentado pessoal $[e]$ ato de sabotagem", ou seja, perfilado entre termos militares desprovidos de quaisquer definições jurídicas. ${ }^{45}$

A Polícia Política, como era de se esperar, não estava alheia a esta disputa de sentido. Note-se que a criminalidade é desprovida de caráter ontológico, sendo uma realidade social construída por meio do processo de criminalização efetuado pelos grupos que têm o poder de influir neste processo. ${ }^{46}$ Isto vale não apenas para os legisladores dos governos militares na forma de tipificação primária do delito político, mas também na tipificação secundária posta em prática pela Polícia Política, ao classificar os suspeitos de cometerem este tipo de delito.

Assim, já em dezembro de 1964 - três anos antes da primeira tipificação do crime de Terrorismo no artigo 25 da Lei de Segurança Nacional de 1967 -, o DOPS do Rio de Janeiro iniciou as investigações referentes ao Setor Terrorismo, encerrando a produção de informações referentes a este assunto somente em 1982. A maior parte da documentação concentra-se entre 1969 e $1972^{47}$, auge e declínio das ações armadas nas cidades. Eram comuns Pedidos de Busca de outros órgãos da Comunidade de Informações, como o requerido pelo Exército em 1976 devido à suspeita de que uma onda de assaltos a lojas de armas, bancos, financeiras e carros pagadores estaria ligada à luta armada. A Polícia Política também mantinha documentação sobre os homens e mulheres que aderiram a lutam armada, como as fichas criminais e prontuários de membros da VPR, OPM e COLINA, datadas a partir de 1969. ${ }^{48}$

Mas a documentação referente ao Setor Terrorismo não dizia respeito somente à luta armada posta em prática pela esquerda no Brasil. Outros grupos internacionais como Baarder-Meinhof, Al-Fatah e Setembro Negro também compunham parte dos relatórios e fichas policiais. A classificação policial nem mesmo se restringia à luta empreendida pela esquerda, na medida em que os grupos anticomunistas surgidos ao final dos anos 1970 eram classificados como "terrorismo de direita", como a Falange Pátria-Nova e a Brigada Anti-Comunista. Acompanhando os atos de violência destes grupos, a Polícia Política produziu relatórios sobre o sequestro do bispo Dom Adriano Hipólito e a explosão de seu automóvel em 1976; empreendeu investigações técnicas sobre a bomba que explodiu na sede da $\mathrm{OAB}$ e na residência de Roberto Marinho ${ }^{49}$; efetuou averiguações sobre ameaças a jornaleiros que vendiam imprensa alternativa; e coletou recortes de jornais sobre os atos de violência efetuados neste período. ${ }^{50}$

\section{Criminosos Políticos e Terroristas: o Banco de Dados sobre os inimigos do regime}

Ainda assim, e sem nenhuma surpresa, era a luta armada fomentada pela esquerda que de fato preocupava a polícia e os órgãos de informação. Por isso, homens e mulheres suspeitos de tomar parte destas ações tinham fichas ou mesmo prontuários produzidos pelo DOPS. Os prontuários reuniam informações mais numerosas e detalhadas acerca de pessoas que tivessem sido presas. Diferentes das fichas, onde constavam as informações mais básicas sobre o suspeito, nos prontuários estavam seus antecedentes e outras informações mais detalhadas acerca dos indivíduos investigados pela polícia.

Neste sentido, foi significativa a transferência de dados feita pela Delegacia de Roubos e Furtos que, em 1969, enviou à Divisão de Ordem Política e Social fichas de pessoas suspeitas de cometerem, com objetivos políticos, assaltos a diversos estabelecimentos. ${ }^{51}$ Mais do que um mero trâmite burocrático interno, aqui notamos o processo de criminalização ${ }^{52}$ efetuado pela instituição policial: aqueles suspeitos de cometer assaltos não mais eram classificados como ladrões ou assaltantes, mas como

\footnotetext{
${ }^{45}$ FRAGOSO, Heleno. Terrorismo e Criminalidade Política..., p. 98.

${ }^{46}$ BARATTA, Alessandro. Criminologia Crítica e Crítica do Direito Penal..., p. 119.

${ }^{47}$ ARQUIVO PÚBLICO DO ESTADO DO RIO DE JANEIRO. Os Arquivos das Polícias Políticas..., p. 27.

${ }^{48}$ ARQUIVO PÚBLICO DO ESTADO DO RIO DE JANEIRO. Fundo Polícias Políticas. Setor Terrorismo, pasta 1.

${ }^{49}$ ARQUIVO PÚBLICO DO ESTADO DO RIO DE JANEIRO. Fundo Polícias Políticas. Setor Terrorismo, Pasta 19.

${ }^{50}$ ARQUIVO PÚBLICO DO ESTADO DO RIO DE JANEIRO. Fundo Polícias Políticas. Setor Terrorismo, Pasta 19a.

${ }^{51}$ ARQUIVO PÚBLICO DO ESTADO DO RIO DE JANEIRO. Fundo Polícias Políticas. Setor Terrorismo, pasta 1.

52 BARATTA, Alessandro. Criminologia Crítica e Crítica do Direito Penal...
} SÆCUlUM - Revista DE HistóRIa [39]; João Pessoa, jul./dez. 2018. 
criminosos "políticos", ou seja, inimigos do Estado e do regime, submetidos a leis muito mais severas. ${ }^{53}$

Evidente que tanto a seleção dos dados que fariam parte destas fichas e prontuários - não raro, informações íntimas e pessoais do suspeito - como a forma como eram significados se davam a partir do arbítrio dos agentes da Polícia Política. Assim, fazer parte de um grupo estudantil, exercer funções de diretoria em sindicatos, compor chapas ou ter participado de campanhas políticas antes ou depois de 1964 eram informações destacadas da trajetória de pessoas fichadas pela polícia, bastando, inclusive, para colocá-las sob suspeita. Foi o caso, por exemplo, de Zilda Paula Xavier Pereira, que, segundo seu prontuário policial ${ }^{54}$, era de fato ligada ao Partido Comunista. Contudo, o mesmo prontuário destaca sua participação nas campanhas contra a carestia; o fato de ter assinado o "Apelo do Conselho Mundial da Paz" em 1953; ter feito parte da Associação de Senhoras de Santa Tereza e ter sido vice-presidente da União Feminina Flamengo: Catete-Glória. Outro exemplo se deu com Padre Alípio, cuja palestra dada em Petrópolis a favor das Reformas de Base e suas participações em reuniões de sindicatos e grêmios estudantis foram registradas nos documentos policiais. ${ }^{55}$

Considerando esta importância dos prontuários na vigilância policial e a preocupação com as ações armadas, Carlos Marighela surge, na documentação produzida pelo órgão, como um dos principais alvos do aparato repressor. Seus prontuários nos DOPS do Rio de Janeiro e da Guanabara ${ }^{56}$ são volumosos, por isto os separamos aqui à guisa de exemplo. Os dados iniciais da documentação remontam à Ditadura do Estado Novo, quando Marighela fora preso. Incluem sua atuação em comícios contra o governo Dutra, seu protesto contra o fechamento do PCB em 1947 e recortes de jornal acompanhando o que a imprensa noticiava sobre ele. Durante a ditadura de 1964, os prontuários incluíam os pedidos de prisão contra Marighela datados de 1966, a ficha de prisão de maio de 1967 e uma compilação de todas as acusações e absolvições referentes a ele durante a república. De fato, a preocupação com Marighela era tamanha que o monitoramento por parte da Polícia Política se deu mesmo após sua morte, em 1969: havia informações detalhadas das polícias do Rio e de São Paulo acerca da operação na qual fora morto, com recortes de jornais sobre o caso sendo zelosamente anexados até 1979. Até mesmo visitas ao túmulo de Marighela eram monitoradas, sendo a detalhada autópsia sobre sua morte anexada ao prontuário.

Da mesma forma, as publicações de Marighela eram analisadas pela Polícia Política como forma de compreender o líder do movimento de oposição - o que é comum numa agência de Segurança Interna. Segundo a polícia, o posicionamento de Marighela sugeria “(...) efeitos mais contundentes nas ações terroristas, para maior impacto emocional na população, e sem levar em contra o possível efeito negativo de tais ações sobre a mentalidade brasileira". De fato, Marighela era um ator político tão importante, que o II Exército admitia ser sua morte causadora de uma desarticulação profunda no esquema subversivo-terrorista. Contudo, sua influência se notava mesmo após a morte, em grupos como Zumbi - que invocava seu nome. A periculosidade de Marighela era tamanha para a Polícia Política que mencioná-lo positivamente como patriota e idealista numa aula tornava-se informe da polícia e motivo de fichamento de quem proferiu o elogio.

Marighela não foi caso isolado, ainda que o mais emblemático pela sua importância para a luta armada. Os prontuários produzidos pelo DOPS traziam fotos, data de nascimento, naturalidade, profissões e dados sobre a vida dos suspeitos de se opor ao Estado, principalmente com relação a seu posicionamento político. Há registros como os da já mencionada Zilda Pereira ${ }^{57}$, fichada desde 1948 , mas membro do Partido Comunista somente a partir de 1951; de Sérgio Furtado, membro do MR-8, no qual constava a lista de assaltos por ele cometido ${ }^{58}$; de Carmem Monteiro Jacomini - cuja absolvição foi citada em recortes de jornais - que teria feito parte de grupos subversivos, recebido treinamento de guerrilha em Jucupiranga, participado de assaltos a partir de 1971 e sido delatada em uma série de interrogatórios ${ }^{59}$; de Stuart Angel, cujo prontuário iniciado em 1969 incluía sua participação em sequestros e assaltos, citações em processos, filiação ao grupo subversivo MR-8,

\footnotetext{
${ }^{53}$ FRAGOSO, Heleno. Terrorismo e Criminalidade Política...

${ }^{54}$ ARQUIVO PÚBLICO DO ESTADO DO RIO DE JANEIRO. Fundo Polícias Políticas, Prontuário 32.355.

${ }^{55}$ ARQUIVO PÚBLICO DO ESTADO DO RIO DE JANEIRO. Fundo Polícias Políticas, Prontuário 28.459.

${ }^{56}$ ARQUIVO PÚBLICO DO ESTADO DO RIO DE JANEIRO. Fundo Policias Políticas. Prontuário 22947 e Prontuário Gb.

7.593.

${ }^{57}$ ARQUIVO PÚBLICO DO ESTADO DO RIO DE JANEIRO. Fundo Polícias Políticas, Prontuário 32.355.

${ }^{58}$ ARQUIVO PÚBLICO DO ESTADO DO RIO DE JANEIRO. Fundo Polícias Políticas, Prontuário Gb 5005.

${ }^{59}$ ARQUIVO PÚBLICO DO ESTADO DO RIO DE JANEIRO. Fundo Polícias Políticas, Prontuário Gb. 5015. 
menções de seu nome por outros investigados fichados na polícia - mesmo após sua morte por agentes do CISA em junho de 1971 - e a consequente monitoração sobre as atividades de sua mãe, Zuzu Angel, que buscava esclarecimentos acerca do desaparecimento do filho ${ }^{60}$; e de Sonia Eliane Lafoz, cujo prontuário revela os codinomes que ela usava, suas participações em assaltos a banco, a filiação ao MR-8, sua participação no sequestro do embaixador da Alemanha e sua fuga para a França. ${ }^{61}$

Contudo, estes prontuários não se restringiam a indivíduos considerados perigosos por estarem envolvidos com a luta armada. Como se sabe, Luiz Carlos Prestes, maior líder comunista brasileiro do período, opôs-se a esta forma de combater a Ditadura de 1964. Não só ele, pois o Partido Comunista Brasileiro, alinhado a Prestes, havia recuado da luta armada e da tentativa de Revolução no início da década de 1960, defendendo a ideia de uma Frente Única com a burguesia nacional e outros setores interessados no desenvolvimento do país. Neste caso, o trabalho seria junto às fábricas, grêmios estudantis e sindicatos a fim de alcançar estes objetivos dentro do jogo político estabelecido. ${ }^{62}$ Não obstante, os agentes do DOPS mantiveram intensa vigilância sobre Prestes, enriquecendo, a partir de 1964, o prontuário que já era produzido desde a década de 1930, com recortes de jornais, informações, campanas e relatórios. ${ }^{63}$ Considerado uma ameaça a Segurança Nacional, Prestes estava sob a lógica da desconfiança policial tanto quanto Carlos Marighela.

\section{Polícia Política e Judiciária}

Além disso, enquanto órgãos da Polícia Civil, os DOPS tinham experiência com a função de polícia jurídica, ou seja, de produzir inquéritos a serem encaminhados para a justiça. $\mathrm{O}$ inquérito é a base do sistema de Justiça brasileiro, no qual a investigação policial ampara a acusação levada às instancias judiciais - promotoria, juiz e júri - de forma pretensamente racional, técnica, linear e evidente, posto que demonstrada por uma metodologia investigativa e lógico-indutiva. ${ }^{64}$

Contudo, as sutilezas investigativas e a familiaridade com o sistema de justiça brasileiro na produção de inquéritos eram habilidades das quais os militares careciam. Os coronéis do Exército, que levavam a cabo os Inquéritos Policiais Militares (IPMs), eram canhestros neste tipo de atividade. Além da proibição do direito a habeas corpus por meio do AI-5 em 1968, os militares também compreenderam que o know how policial no tocante à produção de inquéritos seria um instrumento fundamental para obter prisões na justiça, travestindo, desta forma, o regime de legalidade.

Neste sentido, a documentação policial tinha outra função não necessariamente relacionada à atividade de Inteligência, pois não envolvia segredo ou produção de conhecimento para a tomada de decisões, mas buscava esclarecer crimes e produzir determinados resultados jurídicos. Esta função policial era importante primeiro pela legalidade pretendida na punição aos opositores do regime, visto que toda ditadura busca legitimar-se por meio de seus tribunais. ${ }^{65}$ Note-se que, no decorrer da década de 1960, a legislação referente aos crimes políticos, que na prática são os delitos cometidos contra o Estado e suas autoridades ${ }^{66}$, foi sendo ajustada a nova realidade. Já em 1965, o AI-2 ampliou a competência da Justiça Militar para o julgamento de crimes contra a Segurança Nacional. Em 1967, uma nova Lei de Segurança Nacional foi promulgada, a fim de substituir a lei de 1953, até então vigente. A lei de 1967 foi substituída por outra, em 1969, draconiana, com termos mais castrenses do que jurídicos e de penas muito mais duras ${ }^{67}$ Somente em 1978 esta lei seria substituída por outra versão, no contexto de abertura "lenta, gradual e segura" iniciada por Geisel e conduzida por Figueiredo.

\footnotetext{
${ }^{60}$ ARQUIVO PÚBLICO DO ESTADO DO RIO DE JANEIRO. Fundo Polícias Políticas, Prontuário Gb. 5013.

${ }^{61}$ ARQUIVO PÚBLICO DO ESTADO DO RIO DE JANEIRO. Fundo Polícias Políticas, Prontuário Gb. 5002.

${ }^{62}$ REIS, Daniel. A revolução faltou ao encontro. São Paulo: Editora Brasiliense, 1990.

${ }^{63}$ Arquivo Público do Estado do Rio de Janeiro. Fundo Polícias Políticas, Prontuário Gb. 11328.

${ }^{64}$ LIMA, Roberto Kant. Cultura Jurídica e Práticas Policiais: a tradição inquisitorial. Revista Brasileira de Ciências Sociais, Volume 004, número 010, 1989, e BEATO, Claudio Chaves. Suicídio ou Homicídio: a definição de um fato. Analise e Conjuntura, Fundação João Pinheiro, v.7, n.2, 1992.

${ }^{65}$ SILVA, Francisco Carlos; Karl Schurster; Igor Lapsky; Ricardo Cabral e Jorge Ferreira. (Org.). O Brasil e a Segunda Guerra Mundial. Rio de Janeiro: Multifoco/TEMPO, 2010.

${ }^{66}$ FRAGOSO, Heleno. Terrorismo e Criminalidade Política...; e PAMPLONA, Gustavo. Crimes Políticos, Terrorismo e Extradição...

${ }^{67}$ FRAGOSO, Heleno. Lei de Segurança Nacional: uma experiência antidemocrática. Porto Alegre: Sergio Fabris, 1980.
} 
Assim, uma das funções das Divisões de Polícia Política era produzir inquéritos e outros documentos judiciais acerca de crimes políticos, encaminhando-os aos processos nos tribunais. ${ }^{68} \mathrm{O}$ crime político estava inserido no trabalho normativo de Polícia Judiciária, da qual faziam parte os DOPS - como eram departamentos da Polícia Civil -, padronizando a criminalização da oposição dentro da legalidade pretendida pelos governos militares.

Contudo, a investigação policial não era instrumento de repressão somente quando gerava uma punição decidida nos tribunais. A Polícia Política sabia explorar brechas na lei para obter prisões cautelares, que estavam banalizadas: havia enorme esforço do Ministério Público Militar e da polícia em prender, sendo os acusados tirados de circulação e da resistência política - especialmente no primeiro momento pós-golpe -, como foi o caso de sindicalistas, cujas taxas de absolvições eram superiores às outras categorias. As investigações chegavam à justiça com irregularidades e até mesmo ilegalidades, havendo gente presa cautelarmente sem provas. Estando os acusados presos durante todo o processo até o julgamento final - o que poderia demorar anos - estiveram em detenção mesmo que fossem inocentados ou condenados posteriormente a penas inferiores. ${ }^{69}$

A própria investigação policial em si era uma forma de dominação pelo estigma que gerava nas pessoas sob suspeita da polícia. Como demonstrou Kant de Lima e Silva ${ }^{70}$ ao analisar o cotidiano da polícia investigativa, ser intimado para prestar depoimento, submetido a um interrogatório ou convocado para uma acareação gera um constrangimento no indivíduo frente à sociedade. No caso dos inimigos do Estado, torná-los foragidos ou procurados pela polícia era uma forma de deslegitimar a oposição política, estratégia que se percebe nos cartazes de "Terroristas Procurados" publicados pelo regime, nos quais os criminosos políticos, que "assaltaram, roubaram e mataram país de família" surgiam em fotografias sob os dizeres "ajude a proteger sua própria vida e a de seus familiares". ${ }^{71}$

Sem embargo, a repressão policial não se restringia aos processos legais pretendidos pelos governos militares, pelo estigma de ter sido fichado ou convocado para prestar esclarecimentos ou o medo de se envolver na malha policial. Como se sabe, a repressão do período não envolveu somente a formalidade do trâmite legal: são bem documentados os casos de tortura e outras graves violações de direitos nas instâncias dos DOPS. ${ }^{72}$ Além disso, os agentes dos órgãos da Comunidade de Segurança recorriam a métodos de combate como sequestros, assassinatos e atentados, que em nada se enquadram dentro de atividades policiais legais. Acerca destas operações, consideramos ser necessário outra classificação conceitual, a fim de distingui-las da repressão posta em prática por meio de uma "Justiça Autoritária"73 - na qual inseriam-se os inquéritos e investigações policiais -, da violência direta $e$ totalmente ilegal posta em prática pelas forças de segurança contra seus próprios cidadãos.

\section{Prisões, apreensões, sequestros e assassinatos: entre a legalidade e a ilegalidade}

Para Carlos Fico ${ }^{74}$, a montagem de uma Polícia Política na Ditadura de 1964 estaria relacionada com a Comunidade de Informações - ou seja, de Inteligência - sendo, porém, especificamente distinta. Diria respeito, neste caso, aos órgãos de Segurança, ou seja, militares e policiais que operavam em missões de sequestro, assassinato, prisão, sabotagem e terrorismo, principalmente a partir dos DOICODI. Esta distinção entre as duas atividades é necessária não somente por ser verificada nas fontes

\footnotetext{
${ }^{68}$ Como se vê nas ações penais 19/70, disponível em http://bnmdigital.mpf.mp.br/sumarios/100/003.html, acesso em 25 de junho de 2018, 12:03; 7.423/64 http://bnmdigital.mpf.mp.br/sumarios/100/004.html, acesso em 25 de junho de 2018, 12:04, 189/69 (http://bnmdigital.mpf.mp.br/sumarios/100/007.html, acesso em 25 de junho de 2018, 12:04), por exemplo.

${ }^{69}$ BERNER, Vanessa e BOITEUX, Luciana. (org.). Justiça Autoritária? O judiciário do Rio de Janeiro e a Ditadura militar (1964-1988). Relatório final do projeto de pesquisa apresentado a Fundação de Amparo à Pesquisa do Estado do Rio de Janeiro - FAPERJ - 2015, p. 129.

${ }^{70}$ KANT DE LIMA, Roberto. Cultura Jurídica e Práticas Policiais...

71 https://www.documentosrevelados.com.br/geral/trinta-cartazes-da-memoria-politica/attachment/14359126_101545 52282304530_3916393366196396046_n-1/, e https:/www.documentosrevelados.com.br/geral/trinta-cartazes-da-memoriapolitica/attachment/14359126_10154552282304530_3916393366196396046_n/, acesso em 5 de maio de 2918 , às 11 h52.

${ }^{72}$ ARNS, Dom Evaristo; Arquidiocese De São Paulo. Brasil: Nunca Mais. Petrópolis, RJ: Vozes, 1985.

${ }^{73}$ BERNER, Vanessa e BOITEUX, Luciana. (org.). Justiça Autoritária? O judiciário do Rio de Janeiro e a Ditadura militar (1964-1988).

${ }^{74}$ FICO, Carlos. Espionagem, polícia política, censura e propaganda: os pilares básicos da repressão. In: FERREIRA, Jorge; DELGADO, Lucilia de Almeida Neves (org.) O tempo da ditadura: regime militar e movimentos sociais em fins do século XX. Rio de Janeiro: Civilização Brasileira, 2003. (O Brasil Republicano, vol. 4, 2007). 
referentes aos aparatos de Segurança e Informações da ditadura - documentação que Fico analisa com reconhecido refinamento e rigorosidade - mas também pelo próprio conceito de Inteligência em si, que envolve especificamente a coleta e análise de dados para a produção de conhecimento ou a disputa pelo segredo por parte de agências especializadas.

Entretanto, consideramos como Polícia Política exclusivamente os Departamentos de Ordem Política e Social, devido ao fato de serem especificamente departamentos de polícia investigativa com atribuições relacionadas ao segredo e à atividade de Inteligência no fim de lidar com crime político. A partir destas atribuições, os agentes do DOPS recebiam incumbências de cumprir mandados de captura, buscas e apreensões de material tido como subversivo na forma de panfletos, livros, faixas, camisetas ou bonés; envolviam-se em operações de prisões; efetuavam policiamento ostensivo garantindo a segurança de embaixadas; mantinham "Viaturas Sigilosas" - carros de placa comum com agentes disfarçados para vigilância reservada ${ }^{75}$ - e punham em prática esquemas de segurança em eventos políticos importantes, como a cerimônia de posse presidencial de Costa e Silva em $1967 .{ }^{76}$ Note-se que, com exceção da repressão a materiais tidos como subversivos, todas estas operações são típicas atividades policiais mesmo em regimes democráticos e, incluindo a repressão ao material subversivo, eram todas previstas como atribuições legais da polícia.

Sem embargo, as operações da Comunidade de Segurança não se restringiam a atividades policiais rotineiras e legais, como buscas, apreensões, campanas ou garantias de segurança. Elas envolviam, como bem se sabe, sequestros, assassinatos, atentados e tortura: falamos aqui das práticas mais violentas e deliberadamente ilegais por parte dos governos militares estabelecidos a partir de 1964. Neste sentido, classificamos estas atividades como formas especificas de Operações Encobertas. ${ }^{77}$ Entre estes tipos de operações estão tentativas de assassinatos de líderes de forças adversárias, sabotagem $e$ perpetração de atos terroristas, sendo utilizadas por uma determinada agência a partir de um cálculo no qual se chega a uma "economia de meios" onde a diplomacia é insuficiente e o uso aberto $e$ deliberado da força militar pode ser contraproducente ou arriscado.

Contudo, no caso dos governos militares, falamos operações realizadas pelas forças de Segurança do governo contra seus próprios cidadãos. Neste sentido, não podemos falar especificamente de Operações Encobertas tal qual o conceito normalmente é empregado: o que fazemos é partir deste mesmo conceito para compreender melhor como operavam os órgãos de Segurança. No sentido em que empregamos o termo, o cálculo para o uso de assassinatos, sequestros e atentados não estaria entre a insuficiência da diplomacia e o risco de uma operação militar direta, já que não falamos de uma operação num país estrangeiro. A utilização da violência ilegal por parte dos órgãos de segurança seria fator resultante de três fatores: 1) a introjeção do objetivo de luta contra o comunismo enquanto ameaça à nação, 2) a avaliação de que os procedimentos legais de processo criminal e julgamento na justiça não eram suficientes por serem lentos ou brandos demais, e 3) o temor de uma abertura política que diminuísse ou mesmo eliminasse a ampla discricionariedade desejada pelos setores mais radicais dentre os militares - muitos dos quais compunham os órgãos de segurança. Estes fatores, a nosso ver, explicam os atentados cometidos pelos militares da "linha-dura" diante das tentativas de abrandamento do regime propostas por Castelo Branco, a estruturação dos DOI-CODI a partir da Operação Bandeirantes no final da década de 1960, a atuação intensa contra a luta armada durante o Governo Médici - que teria "aceitado a Guerra"78 - e as reações na forma de atentados durante o período de "distensão", a partir do governo Geisel.

\footnotetext{
${ }^{75}$ Em 1979, a Polícia Federal anexou fichas de terroristas alemães e de terroristas comunistas japoneses com passaportes falsos, a fim de prevenir sua entrada no território brasileiro. ARQUIVO PÚBLICO DO ESTADO DO RIO DE JANEIRO. Fundo Polícias Políticas. Setor Terrorismo, pasta 19. Como exemplo de busca e apreensão, cita-se uma operação na qual foram apreendidos 680 diplomas de conclusão ginasial, 1 pistola Mauser 22, 1 Revólver Smith\&Wesson 32, 1 Revólver Taurus 38, 1 mala com $15 \mathrm{~kg}$ e $850 \mathrm{~g}$ de maconha. Setor DOPS, Pasta 198, Relatório do inquérito sobre acusações de tortura). Sobre materiais apreendidos, ver Relatório anual 1978. ARQUIVO PÚBLICO DO ESTADO DO RIO DE JANEIRO. Setor DGIE, Pasta 277. Sobre operações de prisões, uma das de maior vulto envolveu o caso de desvio de gasolina, denunciado pelo Conselho Nacional do Petróleo. Setor DGIE. Pasta 277, Relatório Anual 1978. Sobre o policiamento em embaixadas e uso de viaturas sigilosas, ver Relatório Reservado. Setor DOPS. Pasta 111.

${ }^{76}$ ARQUIVO PÚBLICO DO ESTADO DO RIO DE JANEIRO. Setor DOPS. Pasta 30. Dossiê 2, Relatório Geral de Fevereiro de 1967.

${ }^{77}$ CEPIK, Marco A. C. Espionagem e democracia..., p. 61-64.

${ }^{78}$ FICO, Carlos. Ditadura militar brasileira: aproximações teóricas e historiográficas. Revista Tempo e Argumento, Florianópolis, v. 9, n. 20, p. 5-74, jan./abr. 2017.
} 
Note-se, por outro lado, que as Operações Encobertas não têm relação necessária - ainda que esta relação seja comum - com as atividades de Inteligência, cujo objetivo é a informação e o conhecimento. Aquelas se relacionam com estas devido à experiência e praticidade de se usar profissionais de espionagem em missões que requerem sigilo e negação de autoria, o que acaba gerando uma rivalidade interna entre os agentes de "ação" - chamados nos EUA de knuckle-draggers, ou "gorilas" - e os de "análise" - chamados de weenies, ou "fracotes"79. No caso dos DOPS, apesar de terem uma função marginal dentro de ambos os sistemas, seu know how foi importante. Investigadores, detetives e delegados forneciam aos DOI-CODI experiência em investigações, campanas e emboscadas vindas dos Esquadrões da Morte desde o fim dos anos 1950, e que foram fundamentais para dar às unidades mistas de militares e policiais a capacidade operacional almejada. ${ }^{80}$ Estes mesmos investigadores, detetives e delegados mantinham os arquivos da repressão de décadas anteriores, pesquisando e produzindo informações que eram frequentemente consultados pelas seções de Inteligência das Forças Armadas e pelo SNI. Não eram "gorilas" como os agentes de ação, nem eram "fracotes" como os especialistas de análise.

\section{Conclusão}

A Polícia Política, principal órgão de Inteligência de Segurança até o fim dos anos 1950, foi readaptada para exercer uma dupla função a partir do golpe de 1964: trabalho investigativo-judiciário $e$ auxílio na análise e processamento de dados no Sistema Nacional de Informações. A primeira era a atividade legal da polícia, o que travestia de legitimidade as ações do Estado, levando os acusados ao sistema de Justiça, estigmatizando-os por meio do inquérito e do fato de tratar-se de criminosos procurados. A segunda objetivava alimentar o sistema de informações e as tomadas de decisão nos governos militares.

Considerando esta aglutinação de atribuições, os DOPS eram instituições por meio das quais o Estado poderia atuar tanto de forma visível quanto secreta, tanto legal quanto ilegalmente. Visível e legalmente, operavam como polícia investigativa e judiciária: produziam inquéritos, arrolavam provas, encaminham suspeitos aos tribunais e tinham discricionariedade nas ruas e no cotidiano. Estas atividades, enquanto previstas institucionalmente no sistema de Justiça brasileiro, pretensamente legitimavam não somente as investigações policiais como os julgamentos delas decorrente e, num sentido mais amplo, a repressão imposta pelo Estado. Secreta e ilegalmente, as Divisões de Ordem Política e Social mantinham grupos, instituições ou mesmo indivíduos sob vigilância reservada, sondando a vida pessoal de cidadãos brasileiros, classificando seu posicionamento político sob a perspectiva da Segurança Nacional e auxiliando os serviços de informações dos governos militares ou seus órgãos de segurança com relação a operações de assassinatos, sequestros e atentados. Em alguns casos, os policiais atuavam nessas operações compondo os DOI-CODI com militares à paisana $e$ envolvendo-se diretamente no Terrorismo de Estado.

Assim, a manutenção dos arquivos da Polícia Política - especialmente fichas e prontuários individuais - foi fundamental para os dois lados nos quais ela atuou. Legalmente, eram documentos policiais de elementos que foram fichados, e que podiam servir ao esclarecimento numa determinada investigação ou inquérito. Confidencialmente, permitiam à polícia e, num sentido mais amplo, aos órgãos da repressão, coagir os cidadãos, manter a sociedade sob intensa vigilância $e$ alimentar a violência extralegal posta em prática pelo Estado. Esta ausência de limites claros entre visibilidade e segredo, legalidade e ilegalidade, concedia flexibilidade à repressão imposta pelos governos militares, sendo uma das permanências ditatoriais nas práticas policiais após o fim da Ditadura de 1964.

\section{eere}

\footnotetext{
${ }^{79}$ CEPIK, Marco A. C. Espionagem e democracia..., p. 64.

${ }^{80}$ MISSE, Michel. Sobre a acumulação social da violência no Rio de Janeiro. Civitas, Porto Alegre, v8, n3, p.371-385, set-dez 2008, e HUGGINS, Martha K. Polícia e Política: ...
} 


\section{RESUMO}

As Divisões de Polícia Política e Social cumpriram destacada função com relação à atividade de Inteligência no Brasil durante boa parte do século XX. Após o golpe civil-militar de 1964, a importância do aparato policial foi redimensionada dentro dos Sistemas de Informações e de Segurança construídos durante a ditadura que se seguiu. Neste sentido, pretendemos analisar $\mathrm{o}$ trabalho policial com relação à Inteligência doméstica dentro destes sistemas e, num sentido mais amplo, do projeto repressor pretendido pelos governos militares. Tal análise, tendo como fonte a documentação produzida pela Polícia Política no período, se dará a partir da definição conceitual de Inteligência como um trabalho que envolve o segredo e destina-se à coleta e análise de dados a fim de produção de conhecimento. Considerando tratar-se de um organismo policial, levamos em conta que a produção destas informações efetuava um processo de criminalização da oposição política ao regime. O que pretendemos demonstrar é que o know how policial e seu banco de dados foram fundamentais para $\mathrm{o}$ projeto de Segurança pretendido naquele contexto, tanto pela atuação do órgão enquanto polícia jurídica como na produção de informações que alimentava o referido sistema.

Palavras Chave: Polícia Política; Inteligência; Ditadura de 1964.

\section{ABSTRACT}

The Political and Social Police Divisions fulfilled a prominent role in relation to Intelligence activity in Brazil during much of the 20th century. After the civil-military coup of 1964 , the importance of the police apparatus was redimensioned within the Information and Security Systems built during the dictatorship that followed. In this sense, we intend to analyze the police work in relation to the domestic Intelligence within these systems and, in a broader sense, of the repressor project intended by the military governments. Such analysis, having as source the documentation produced by the Political Police in the period, will be given from the conceptual definition of Intelligence as a work that involves the secret and is destined to the collection and analysis of data in order to produce knowledge. Considering that it is a police organization, we take into account that the production of this information carried out a process of criminalization of the political opposition to the regime. What we want to demonstrate is that the police know-how and its database were fundamental for the Security project intended in that context, both by the agency's acting as a legal police and in the production of information that fed the said system.

Keywords: Political Police; Intelligence; Dictatorship of 1964.

Artigo recebido em 02 jul. 2018.

Aprovado em 17 set. 2018. 